\title{
OS CAMINHOS DE PROTEÇÃO INTERNACIONAIS ACESSÍVEIS ÀS VÍTIMAS DE VIOLAÇÓES DE DIREITOS HUMANOS
}

\author{
THE WAYS TO ACCESSIBLE INTERNATIONAL PROTECTION TO HUMAN RIGHTS VIOLATION \\ VICTIMS
}

Lorena Silva Santos

Advogada

Mestranda em Direitos Humanos pela Universidade Federal de Pernambuco. Especialista em Direito do Estado pela Universidade Federal da Bahia.

lenalorenassantos@gmail.com

\section{RESUMO}

O presente artigo parte do pressuposto de que a conscientização dos direitos é tão essencial quanto o acesso às informaçóes de como protegê-los em caso de violaçóes. Neste sentido, esta pesquisa tem o objetivo de analisar a possibilidade de acesso ao mecanismo universal de proteção após uma busca não exitosa da vítima ao sistema regional interamericano, sob a possível problemática do Comitê de Direitos Humanos da ONU encontrarse impedido de analisar o caso, devido este já ter sido decidido no plano regional pela Corte Interamericana, com o esgotamento de todas as formas de impugnação, isto é, já ter ocorrido a coisa julgada. Entretanto, com base numa metodologia exploratória de cunho essencialmente bibliográfico, legislativo e jurisprudencial, buscou-se perquirir se a ausência de tutela pela Corte Interamericana não comprometeria o fim maior de salvaguardar os direitos humanos a que se destina o sistema internacional, ainda que numa perspectiva reparatória, e se assim tal constatação não seria capaz de tornar inócua a discussão acerca da positivação ou aplicação da teoria da coisa julgada implícita do direito internacional ao singular sistema de proteção de direitos humanos.

Palavras-chave: Subsidiariedade. Coisa julgada. Corte Interamericana de Direitos Humanos. Comitê de Direitos Humanos da ONU. 


\section{ABSTRACT}

This article assumes that awareness of rights is as essential as access to information on how to protect them in the event of violations. In this sense, this research aims to analyze the possibility of access to the universal protection mechanism after an unsuccessful search of the victim to the inter-American regional system, under the possible problem of the ONU Human Rights Committee being prevented from analyzing the case, as the InterAmerican Court has already decided at the regional level, with the exhaustion of all forms of impugnation, that is, the case has already occurred. However, based on an exploratory methodology that was essentially bibliographical, legislative and jurisprudential, it was sought to determine whether the absence of protection by the Inter-American Court would not compromise the greater purpose of safeguarding the human rights of the international system, even though from a perspective and if such a finding could not render the debate about the positivization or application of the theory of the implicit judgment of international law to the singular system of protection of human rights impossible.

Keywords: Subsidiarity. Res judicata. Inter-American Court of Human Rights. ONU Human Rights Committee.

Data de submissão: 29/03/2018

Data de aceitação: 30/07/2018

\section{SUMÁRIO}

INTRODUÇÃO 1. METODOLOGIA 2. LIMITE JURÍDICO À PROTEÇÃO DOS DIREITOS HUMANOS NO PROCESSO INTERNACIONAL. CONSIDERAÇÓES FINAIS. 


\section{INTRODUÇÁO}

Os direitos humanos como frutos de uma longa luta travada no plano das mentalidades e no front social e político ${ }^{1}$ podem ser apreendidos, com fulcro na liberdade e na igualdade, como um conjunto de direitos essenciais, indispensáveis a uma vida humana digna.

Em que pese a discussão acerca da natureza e origem dos direitos humanos, ${ }^{2}$ as necessidades humanas variam e, de acordo com o contexto histórico de uma época, novas demandas sociais são traduzidas juridicamente e inseridas na lista dos direitos humanos, cujo caminho da interdisciplinaridade, conduz a um olhar mais integral sobre a sua efetividade, proporcionando um espaço de diálogo aberto entre os diversos saberes, uma interconectividade do conhecimento propulsora de ações mais inclusivas.

Malgrado não se possa condicionar o progresso da proteção dos direitos humanos, exclusivamente, ao avanço normativo institucional, tendo em vista que as reivindicaçóes em outros espaços de luta se mostraram ao longo da história da humanidade imprescindíveis à sua efetividade, ${ }^{3}$ o Direito, dentre os saberes, enquanto ferramenta para a garantia dos direitos humanos, busca conferir, por meio dos seus institutos jurídicos, uma procedimentalização do anseio de justiça, sob o crivo da equidade.

Assim, na seara normativa, com vistas a se evitar interpretaçóes divergentes e a duplicação de procedimentos capazes de gerar o enfraquecimento e o abalo da confiança no sistema internacional de direitos humanos, passou-se a discutir nos últimos anos a necessidade de criação de meios de coordenação entre os diversos mecanismos global e regional de responsabilizaçáo do Estado, sob a proposta de alinhamento procedimental, frente ao desenvolvimento da proteção dos direitos humanos, que é pautado na diversidade de diplomas normativos internacionais. ${ }^{4}$

Nesse sentido, é possível encontrar instrumentos que refletem essa preocupação, quais

$\overline{1}$ HUNT, L. A invençáo dos Direitos Humanos uma história, 2016, pp. 13-33.

2 Teorias subjetivistas (releitura do jusnaturalismo e enfoque na liberdade individual, v.g. Rawls e Dworkin), teorias intersubjetivistas (identificação de valores comuns aos seres humanos, v.g. Habermas), teorias objetivas (buscam encontrar uma ética material dos valores, identificando os direitos caracterizados pela universalidade, atemporalidade e preexistência), perspectiva positivista (direitos humanos são aqueles positivados no ordenamento jurídico) ou realista (Noberto Bobbio aduz que o problema fundamental em relação aos direitos do homem, hoje, não é tanto o de justifica-los, mas o de protegê-los). (GARCIA, Leonardo de Medeiros (Org.). Legislação Internacional Comentada. Salvador: Juspodium, 2016. p. 23). 3 PRONER, C. Projeto Universitários pela Paz da ONU-BR - Naçôes Unidas no Brasil. Youtube, [21 de janeiro a 1 de fevereiro de 2013].

4 RAMOS, A. C. de. Processo Internacional de Direitos Humanos, 2015. p. 345. 
sejam, a Declaração de Viena, em seu item 4 ao recomendar que "Os órgãos e agências especializadas relacionados com os direitos humanos devem, portanto, reforçar a coordenação de suas atividades com base na aplicação coerente e objetiva dos instrumentos internacionais de direitos humanos."

No Sistema Regional de proteção dos direitos humanos, a Convenção Americana de Direitos Humanos, ao aduzir em seu artigo 64 que a Corte Interamericana de Direitos Humanos é competente para emitir Parecer Consultivo sobre todo tratado de direitos humanos aplicável aos Estados americanos, traz o juízo de compatibilidade como instrumento de coordenação.

Em âmbito interno, a Recomendação do Conselho Nacional de Justiça - CNJ n. ${ }^{\circ} 49$, do ano de 2014, pautada no Protocolo de Istambul, trouxe um manual a ser utilizado pelos magistrados na documentação e investigação de casos de crimes de tortura, visando a coordenação procedimental no Brasil, numa proposta de simetria com a ordem internacional.

Como objeto de estudo dessa pesquisa está o Protocolo Facultativo ao Pacto Internacional de Direitos Civis e Políticos ao exigir em seu artigo $5^{5}$ que a questão sob análise do Comitê de Direitos Humanos da ONU não deva estar em curso perante outra instância internacional. Esta norma como um requisito de apreciação das questóes de violaçóes de direitos humanos, representa um meio de coordenação das demandas a serem apreciadas pelo Comitê de Direitos Humanos da ONU.

Todavia, questiona-se se esta condição não seria insuficiente, capaz de levar a uma inconsistência de todo o sistema de proteção dos direitos humanos, diante da possibilidade de pairar sobre um caso concreto já analisado, isto é, que não esteja mais em curso em outra instância, uma nova avaliaçáo pelo Comitê de Direitos Humanos? Posto que no referido Protocolo Facultativo não se estipulou como requisito de admissibilidade de uma

\footnotetext{
“Art. 5 - 1. O Comitê examinará as comunicações recebidas em virtude do presente Protocolo, tendo em conta informaçóes escritas que lhe sejam submetidas pelo indivíduo e pelo Estado Parte interessado. 2. O Comitê não examinará nenhuma comunicação de um indivíduo sem se assegurar de que: a) A mesma questão náo esteja sendo examinada por outra instancia internacional de inquérito ou de decisão;"
} 
petição, a inexistência de coisa julgada ${ }^{6}$ internacional, mas tão somente a litispendência. ${ }^{7}$

\section{METODOLOGIA}

A metodologia aplicada para a realização da pesquisa proposta teve natureza exploratória, cujas principais fontes de pesquisas foram a bibliográfica, legislativa, jurisprudencial e documental, com ênfase em materiais doutrinários e acadêmicos já elaborados, incluindo livros, publicações periódicas, artigos científicos. Ademais, legislaçóes, documentos e decisóes dos órgãos que compóem o sistema internacional de proteção dos direitos humanos.

Nesse sentido, a presente pesquisa tem abordagem metodológica essencialmente dogmática, com detida análise do Direito vigente (nacional e internacional), com o objetivo de não só contribuir para a discussão dos limites à promoção dos Direitos Humanos no atual contexto de recrudescimento e neo-conservadorismo, como também fornecer uma resposta adequada para o problema enfrentado.

\section{LIMITE JURÍDICO À PROTEÇÁO DOS DIREITOS HUMANOS NO PRO- CESSO INTERNACIONAL}

As vítimas de violaçóes de direitos humanos devem esgotar os meios ou recursos internos disponíveis para a concretização do direito protegido, uma vez que se reconhece como dever primário do Estado a função de prevenir violaçôes de direitos ou ao menos reparar os danos causados. Com isso, somente após seu fracasso, a proteção internacional pode ser invocada. A atuação dos mecanismos internacionais, portanto, seja o regional, que

\footnotetext{
Haverá coisa julgada material a partir do momento em que não for mais cabível qualquer recurso ou tendo ocorrido o exaurimento das vias recursais, em que a decisão não mais poderá ser alterada ou desconsiderada em outros processos. NEVES, D. A. A. Manual de Direito Processual Civil, 2011. p. 530. 7 Haverá litispendência quando dois ou mais processos idênticos existirem concomitantemente, caracterizando-se a identidade pela verificação no caso concreto da tríplice identidade (mesmas partes, mesma causa de pedir e mesmo pedido). NEVES, D. A. A. Op., cit., p. 349.
} 
no caso sob estudo ${ }^{8}$ é o interamericano, e seja o universal, onusiano, é permitida apenas subsidiariamente ao insucesso da tentativa nacional de resolução de conflito. ${ }^{9}$ As investigaçóes das violaçóes de direitos humanos, além de tratarem de conflito de interesses na ordem interna, refletem fenômenos político-sociais que a ordem internacional também enfrenta, como bem pronuncia Francisco Rezek ao aduzir que:

Não deve existir no mundo contemporâneo um país tão desarvorado a ponto de que sua ordem jurídica interna dependa, para que suas regras de maior peso sejam eficazes nas horas mais graves, de uma conjugação política de circunstâncias favoráveis, de uma não-oposição ao interesse e à estratégia dos núcleos de poder. É isso entretanto, em linhas rudes, o que se passa ainda - ou talvez mais que nunca - com a ordem internacional. ${ }^{10}$

Neste cenário, surge a discussão quanto à efetividade dos direitos humanos mediante a perspectiva da autoridade da coisa julgada, cujo pano de fundo é se referido instituto normativo responde a um anseio de restabelecimento da paz, com a reparação de danos ou a uma necessidade dogmática de estabilidade jurídica, esvaziada de efetividade social. Posto que, malgrado, os mecanismos global e regional tenham a nobre missão em comum de tutelar os direitos humanos, cada um deles comporta estrutura bem distinta, que pode vir a comprometer a satisfatividade da pretensão.

Nesse sentido, o estudo do acesso aos meios de defesa dos direitos humanos no plano internacional à luz da aplicabilidade do instituto da coisa julgada no processo internacional de proteção dos direitos humanos vem ganhando importância teórica e prática devido ao crescimento expressivo de informaçóes veiculadas na sociedade, quanto à tutela dos direitos humanos pelo sistema de petiçóes individuais contido nos mecanismos universal

$8 \quad$ Caso Nogueira de Carvalho e outro versus Brasil ( $n^{\circ} .12 .058$ com sentença da Corte Interamericana de Direitos Humanos prolatada em 28/11/2006), referindo-se ao homicídio de advogado defensor de direitos humanos no Estado do Rio Grande do Norte por membros de esquadráo da morte, em que o Brasil fora acusado de não ter investigado e punido, a contento, os responsáveis pela morte do Sr. Gilson. Entretanto, a Corte considerou a açáo improcedente, com base no entendimento de que a obrigação de investigar, perseguir criminalmente e punir os responsáveis pelas violaçóes de direitos humanos é uma obrigação de meio e náo de resultado, e que portanto o Brasil se esforçou para cumprir sus obrigaçóes de garantia de direitos humanos, ainda que tenham sido pífios os resultados (apenas um dos pretensos responsáveis foi processado e absolvido pelo Júri popular). (RAMOS, A. C. de. Processo Internacional de Direitos Humanos, 2015, p. 448).

9 RAMOS, A. C. de. Op. Cit. pp. 76-78.

10 REZEK, apud CALDEIRA BRANT. A autoridade da coisa julgada no Direito Internacional Público, 2002, prefácio. 
e regional de proteção internacional. Visibilidade conferida ao processo internacional de proteção dos direitos humanos em território brasileiro a partir da Constituição de 1988, uma vez que a redemocratização do Brasil foi o marco inicial na história da intensificação da busca pela efetividade dos direitos humanos no País, cuja Convenção Interamericana para Prevenir e Punir a Tortura, em 20 de julho de 1989, inaugurou o processo de vinculaçáo do Brasil a Tratados Internacionais de Direitos Humanos pós-redemocratização. ${ }^{11}$

Todavia, em que pese a subsidiariedade da atuação protetiva internacional, é defensável a disseminação do entendimento de que a proteção dos direitos humanos não se resume ao domínio reservado do Estado, ${ }^{12}$ tornando cada vez mais próximos dos indivíduos os meios de acesso às instâncias internacionais de proteçáo. Diante desse marco ideológico, entende que pode ser crescente a quantidade de casos de violaçóes de direitos humanos a serem submetidos à ordem protetiva internacional.

O estudo da temática proposta neste artigo, portanto, está centrado no postulado da dignidade da pessoa humana no campo do direito internacional, que nas palavras do Professor Francisco Rezek é:

Um ramo do direito mais do que simplesmente nos circunda, de certo modo, ele desaba sobre nós, com sua riqueza conceitual, com o fascínio de sua história, com a extraordinária grandeza da causa a que serve sua disciplina; e ao mesmo tempo nos comove pela pungente modéstia dos seus meios de afirmação e prevalência, pela intrínseca fragilidade que o torna objeto frequente da mistificação, da evasão, da afronta pura e simples. ${ }^{13}$

O discurso da segurança jurídica introduz a linha argumentativa em defesa da positivação ou aplicação da teoria da coisa julgada material implícita do direito internacional ao singular sistema de proteção internacional de direitos humanos, posto que para estes estudiosos a coisa julgada material ao impedir a revisitaçấo do caso consubstanciado numa decisão garante a estabilização das relaçôes jurídicas, fator indispensável à sobrevivência de

$\overline{11}$ PIOVESAN, F; AMARAL JR, A; JUBILUT, L. L. Hierarquia dos Tratados Internacionais de Proteção dos Direitos Humanos: Jurisprudência do STF. In: AMARAL Jr., A; JUBILUT, L.L. (Orgs.) O STF e o Direito Internacional dos Direitos Humanos, 2009, v. 01, p. 123-145.

12 LUCK, A. S. O sistema internacional de direitos humanos.

13 REZEK, F. Prefácio. In: CALDEIRA BRANT, Leonardo Nemer. A autoridade da coisa julgada no Direito Interacional Público, 2002. 
uma sociedade democrática. ${ }^{14}$

Para a doutrina positivista, a segurança corporificada na autoridade da coisa julgada se afigura como um dos valores mais importantes do plexo axiológico da experiência jurídica, sinalizando a importância da estabilidade e da previsibilidade nas relaçóes como meio para a concretização do direito justo, uma vez que a ideia de justiça liga-se intimamente à ideia de ordem. O que impende destacar que o efeito da coisa julgada do ponto de vista formal ${ }^{15}$ não pode se dissociar do seu efeito material, devido à boa fé, ao interesse do Estado em preservar o crédito e à confiança na comunidade internacional.

O direito internacional apresenta características próprias que o distingue do direito interno, mas não são capazes de afastar a aplicabilidade do princípio da autoridade da coisa julgada no processo internacional de proteção dos direitos humanos, uma vez que a sentença internacional existe no interesse geral, tanto quanto no interesse das partes, corroborando com o entendimento de que a garantia da manutenção da estabilidade jurídica num plano internacional a todos importa como uma solução de garantia democrática.

Assim sendo, é que se por um lado, a coisa julgada é um instituto que não está previsto nos Tratados que regem os mecanismos interamericano e o universal do Comitê de Direitos Humanos da ONU, por outro, há como considerá-la regra implícita ao sistema internacional de direitos humanos ${ }^{16}$, diante da realidade de órgãos criados por tratados de direitos humanos, tais como a Corte Interamericana de Direitos Humanos e o Comitê de Direitos Humanos estarem utilizando-se constantemente dos conceitos da teoria geral da responsabilidade internacional do Estado, tais como esgotamento de recursos internos, imputação e obrigação de reparação. Assim, considerando a coisa julgada um instituto da teoria geral da responsabilidade internacional do Estado, apto a ser utilizado no processo internacional de proteção dos direitos humanos pelos mecanismos de proteção supracitados, implícita se encontra essa regra no sistema de proteção dos direitos humanos.

\footnotetext{
$\overline{14}$ NEVES, D. A. A. Manual de Direito Processual Civil, 2011. p. 549.

15 Ocorre a coisa julgada formal quando não mais for possível qualquer recurso ou tendo ocorrido o exaurimento das vias recursais a sentença transitar em julgado, ocorrendo, assim a preclusão máxima, que impede a modificação da decisão por qualquer meio processual dentro do processo em que foi proferida. Configura um fenômeno endoprocessual. (NEVES, D. A. A. Op. Cit. pp. 529-530).

16 Embora tanto a primeira e a II Convenção de Haia de 1899 e de 1907, respectivamente, quanto o próprio Estatuto da CIJ, em seus arts. 59 e 60, admitam claramente a legalidade da aplicação do princípio da autoridade da coisa julgada, o presente projeto de pesquisa tem como objeto de estudo a sua aplicabilidade no processo de responsabilização dos Estados iniciado por petiçôes de particulares no mecanismo regional e no Comitê de direitos humanos, da ONU.
} 
Nessa linha de intelecção, com o fim de se afastar a possível dupla apreciação de um mesmo caso por mecanismos distintos, impor reserva na adesão ao Protocolo Facultativo ao Pacto Internacional de Direitos Civis e Políticos, tal como fizeram alguns Estados europeus contratantes da Convençáo Europeia de Direitos Humanos ${ }^{17}$ poderia vir a configurar uma fundamentação legítima em prol da aplicação da coisa julgada material.

Ademais, partindo-se do entendimento de que inexiste eficácia vinculante das deliberaçóes do Comitê de Direitos Humanos, pode-se afirmar numa perspectiva da hierarquização dos procedimentos de responsabilização do Estado, que a decisão revestida de caráter jurisdicional do mecanismo interamericano goza de grau superior à decisão de um órgáo náo jurisdicional, como o Comitê de Direitos Humanos da ONU, ainda que doutrinariamente entendido como um órgão quase judicial. ${ }^{18}$

Não há no meio acadêmico um posicionamento uníssono sobre o caráter vinculante das decisões do Comitê de Direitos Humanos.

De um lado estão os defensores do caráter não vinculante destas deliberaçóes, que enfatizam a ausência de disposição expressa nos tratados internacionais. Apontam, também, o estágio atual do Direito Interacional dos Direitos Humanos, que exigiria a cooperaçáo dos Estados para o cumprimento de suas normas. ${ }^{19}$

A falta de eficácia vinculante das decisóes proferidas pelo Comitê de Direitos Humanos da ONU fortalece o discurso do respeito à definitividade da decisão prolatada pela Corte Interamericana de Direitos Humanos, e pois o de impedimento de se levar a mesma questão já decidida pela Corte Interamericana ao Comitê de Direitos Humanos da ONU.

O entendimento quanto ao caráter não vinculante das decisões do Comitê de Direitos Humanos da ONU é objeto de crítica no discurso da Professora Juliana Neuenschwader Magalhães. Referida argumentação inicia o caminho contrário à positivação ou aplicação da teoria da coisa julgada implícita do direito internacional ao singular sistema de proteção internacional de direitos humanos:

\footnotetext{
17 RAMOS, A. C. de. Processo Internacional de Direitos Humanos, 2015, p. 363.

18 "Os mecanismos quase judiciais são aqueles previstos na fase de controle da observância de direitos humanos, na qual analisam-se petiçôes individuais e interestatais que se insurgem contra violaçóes de direitos humanos e pleiteiam reparaçáo, como exemplo, cite-se o Comitê de Direitos Humanos com a capacidade de processar tais petiçóes” (RAMOS, A. C. de. Op. Cit. p. 363).

19 RAMOS, A. C. de. Processo Internacional de Direitos Humanos, 2015, pp. 363-364.
} 
Assim é que, em nome da preservação da paz entre os Estados soberanos, concebeu-se um direito das gentes que se constituiu em verdadeiro "direito à guerra" ou, nas palavras de Kant, um direito "para a guerra". Por isso, quando, a partir dos instrumentos do direito internacional, pretende-se dar feição jurídica a uma organização do tipo da ONU, que tem por missão a garantia da paz e a salvaguarda dos direitos humanos, essa ordem não encontra uma unidade política ou jurídica na afirmação de qualquer soberania 'global'. Ou seja, a ONU deve desempenhar sua tarefa sempre com respeito ao princípio da não-intromissão e, portanto, da primazia da soberania estatal. $\mathrm{O}$ paradoxo é que, de um lado, não se concebe a ONU como uma instância política capaz de tomar decisóes que vinculem os Estados e, de outro, espera-se da ONU e do direito internacional uma garantia da paz entre os Estados. ${ }^{20}$

Ainda sob o prisma da hierarquização dos procedimentos de responsabilização do Estado, com base, todavia, em premissa contrária à anteriormente invocada, o caráter universalista da ONU há de se sobrepor ao regional interamericano, legitimando uma possível rediscussão de um caso, cuja reparação não fora concedida.

Nesse sentido, impende concluir que a falta de positivação do instituto da coisa julgada junto ao Protocolo Facultativo ao Pacto Internacional dos direitos Civis e Políticos fora a real intenção dos legisladores internacionais. Afinal, quando quiseram utilizar conceitos da teoria geral da responsabilidade do Estado o fizeram expressamente, a exemplo do artigo $5^{\circ}$, do Protocolo Facultativo ao Pacto Internacional de Direitos Civis e Políticos, em suas alíneas "a" com o instituto da litispendência e "b" com o esgotamento de recursos internos.

O princípio da autoridade da coisa julgada náo pode ser dissociado do corpo social a que se refere a sua aplicabilidade e do fim maior que alicerça todo o sistema de proteção internacional de direitos humanos, qual seja, a dignidade da pessoa humana. ${ }^{21}$ Assim, comungando dessa idealização, encontra-se a corrente que defende a força vinculante das decisóes do Comitê de Direitos Humanos da ONU, sob pena de se diagnosticar incongruente o sistema universal de proteção:

A interpretação sistemática e finalística dos tratados de direitos humanos deve ser feita em prol do aumento da carga protetiva, já que os mesmos foram celebrados justamente para proteger o indivíduo e não para dar vantagens materiais aos contratantes. Além disso, o poder

20 MAGALHÃES, J. N. Paradoxos da democracia: A soberania dos direitos humanos. Revista Latino-Americana de Estudos Constitucionais, 2010, p. 485-499.

21 SOARES, R.M.F. O princípio constitucional da dignidade da pessoa humana, 2010, p. 149. 
de apreciar as petiçốes pelos Comitês foi conferido, em geral, graças à adesão à cláusula facultativa. Logo, o Estado pode aderir ao tratado sem concordar com tais cláusulas, ficando imune ao sistema de petiçôes. Mas se expressamente aceita tal sistema seria ilógico considerar as deliberações finais dos mesmos como meros conselhos ou recomendaçôes. ${ }^{22}$

Em linhas conclusivas, o princípio da prevalência da norma mais favorável à pessoa humana, régle d'or da máxima proteção, pode ser encontrado em parte dos Tratados, tanto em âmbito regional quanto universal, a exemplo do Pacto das Naçóes Unidas sobre direitos civis e políticos (artigo 5); do Pacto Internacional de Direitos Econômicos, Sociais e Culturais (artigo 5); da Convenção Europeia de Direitos Humanos (artigo 60); da Convenção Americana de Direitos Humanos (artigo 29, b). Assim, as decisóes prolatadas devem buscar alcançar a maior efetividade dos direitos, o que permite apreender que o esgotamento de um mecanismo não exaure o direito da vítima de utilizar-se de outro no caso da reparação não ter sido obtida, não se podendo impedir, portanto, que a vítima percorra outro caminho na busca por maior proteção. ${ }^{23}$

\section{CONSIDERAÇÓES FINAIS}

Após criteriosa análise sobre a efetivação dos direitos humanos frente às possibilidades de acesso aos sistemas internacionais de proteção, seja o regional interamericano, seja o universal, onusiano, percebeu-se que a discussão em torno da coisa julgada, enquanto instituto jurídico a ser considerado como pressuposto de admissibilidade das petições individuais de vítimas levadas ao Comitê de Direitos Humanos, reverberou em duas posiçôes contrárias de entendimento. A segurança jurídica como instrumento de estabilização das relaçóes jurídicas, imprescindível à uma sociedade democrática, inaugura a linha de fundamentação pautada na defesa da positivação ou aplicação da teoria da coisa julgada implícita do direito internacional ao singular sistema de proteção internacional de direitos humanos, posto que o respeito à decisão da Corte Interamericana de Direitos Humanos por outros mecanismos de proteção internacional confere garantia de estabilidade jurídica

\footnotetext{
22 RAMOS, A. C. de. Processo Internacional de Direitos Humanos, 2015, pp. 363-364.

23 TRINDADE, A. A. C. Co-existence and co-ordination of mechanism of international protection of human rights - at global and regional levels. In: 202 Recueil des Cours de l'Académie de Droit International de La Haye, 1987, p. 409.
} 
que a todos importa, como fim último do próprio sistema internacional de proteção dos direitos humanos.

Na sequência dessa linha de pensamento, a coisa julgada, enquanto instituto da teoria geral da responsabilidade internacional do Estado, ${ }^{24}$ pode ser considerada como uma regra implícita ao sistema de proteção internacional de direitos humanos, tal como se observa nos conceitos de esgotamento de recursos internos, imputação e obrigação de reparação. Nesse sentido, estão os Estados europeus ao impor reserva na adesão do Protocolo Facultativo ao Pacto Internacional de Direitos Civis e Políticos, com o fito de se impedir dupla apreciação de um mesmo caso por mecanismos distintos.

Ademais, o respeito à decisão da Corte Interamericana de Direitos Humanos que repercute na impossibilidade de análise do mesmo caso pelo Comitê de Direitos Humanos da ONU, e portanto na defesa da positivação ou aplicação da teoria da coisa julgada implícita do direito internacional ao singular sistema de proteção internacional de direitos humanos, encontra guarida na fundamentação de que as decisóes da Corte são revestidas de definitividade, enquanto as decisões do Comitê da ONU não guardam força vinculante.

O caráter não vinculante das decisóes da ONU, por outro lado, é objeto de críticas por parte de estudiosos que entendem ser um paradoxo a concepçáo da referida organização como uma instância política incapaz de tomar decisóes que vinculem os Estados em paralelo à esperança de que dela advenha a garantia da paz.

Assim resta inaugurada a escrita sobre a linha de argumentação que dialoga com a efetividade da decisão, uma vez que a autoridade da coisa julgada não pode estar dissociada do objeto social ao qual se presta, qual seja, o respeito à dignidade humana, posto que uma sentença prolatada pela Corte Interamericana de Direitos Humanos que não confere total reparação à vítima náo pode ser capaz de afastar o direito da mesma utilizar outro mecanismo.

A régle d’or da máxima proteção, o princípio da prevalência da norma mais favorável à pessoa humana vem sedimentar o entendimento segundo o qual a coisa julgada náo pode ser considerada como um valor absoluto, que a priori e em qualquer situação se mostre mais importante do que a efetiva reparação à vítima.

Neste sentido, seria legítimo o afastamento da tese de positivação ou aplicação da teoria $\overline{24 \quad \text { Artigos } 59}$ e 60 do Estatuto da Corte Internacional de Justiça. 
da coisa julgada implícita do direito internacional ao singular sistema de proteção internacional de direitos humanos, frente à consideração de casos de vítimas que não tiveram seus pleitos de reparação atendidos na Corte Interamericana de Direitos Humanos, permitindo-se com isso a busca pela acolhida do Comitê de Direitos Humanos da ONU, enquanto órgão do sistema global de proteção dos direitos humanos, criado a partir do Primeiro Protocolo Facultativo do Pacto Internacional de Direitos Civis e Políticos, cuja competência é receber petiçōes individuais de violaçôes de direitos humanos dirigidas contra Estados. ${ }^{25}$

Assim sendo, a aceitabilidade da coisa julgada frente a uma decisão da Corte Interamericana de Direitos Humanos que não conferiu total reparação à vítima funcionaria como um "manto protetor sem nada a ser protegido no caso concreto" conforme preleciona Cândido Rangel Dinamarco ${ }^{26}$ o que torna clara e direta a ofensa ao fim "autoevidente" ${ }^{27}$ do sistema internacional de proteção dos direitos humanos.

$\overline{25} \quad$ O caso Nogueira de Carvalho e outro versus Brasil explicitado na referência de número 8 haveria de poder ser submetido à análise da ONU, por parte de seu Comitê de Direitos Humanos, diante do não acolhimento do pleito reparatório pela Corte Interamericana de Direitos Humanos.

26 DINAMARCO, C. R. Relativizar a coisa julgada material. Revista de Processo, n. 127, pp. 245 249.

27 Adjetivo conferido aos direitos humanos e objeto de discussão na obra da historiadora Lynn Hunt em "A invenção dos Direitos Humanos uma história". A Página, 2016. 


\section{REFERÊNCIAS}

BRANT, L. N. C. A autoridade da coisa julgada no Direito Interacional Público. Rio de Janeiro: Forense, 2002.

CANÇADO, A. A T. Co-existence and co-ordination of mechanism of international protection of human rights - at global and regional levels. In: 202 Recueil des Cours de l'Académie de Droit International de La Haye, 1987, p. 409.

DINAMARCO, C. R. Relativizar a coisa julgada material. Revista de Processo, São Paulo, n. 109, 2003.

GARCIA, L. M. de. (Org.). Legislaçáo Internacional Comentada. Salvador: Juspodium, 2016.

HUNT, L. A invençáo dos Direitos Humanos uma história. Curitiba: A Página, 2016.

MAGALHÃES, J. N. Paradoxos da democracia: A soberania dos direitos humanos. Revista Latino-AmericanadeEstudosConstitucionais, 2010.v.6.p.485-499. Disponível em:<https://books.google.com.br/books?id=-mTyxlsyFzQC\&pg=PA485\&lpg=PA485\&dq=paradoxo>.

NEVES, D. A. A. Manual de Direito Processual Civil. Rio de Janeiro: Método, 2011.

PIOVESAN, F; AMARAL JR, A; JUBILUT, L.L. Hierarquia dos Tratados Internacionais de Proteçâo dos Direitos Humanos: Jurisprudência do STF. In: AMARAL, Jr; JUBILUT, L. L. (Orgs.) O STF e o Direito Internacional dos Direitos Humanos. São Paulo: Quartier Latin, 2009, v. 01, p. 123-145. Disponível em: <http://www.dhnet.org.br/direitos/ militantes/flaviapiovesan/piovesan_tratados_sip_stf.pdf >. Acesso em: 25 ago. 2014.

PRONER, C. Projeto Universitários pela Paz da ONU-BR - Nações Unidas no Brasil. Youtube. Disponível em: <https://m.youtube.com/watch?v=M-QWKLYMMK8>.

RAMOS, A. C. de. Processo Internacional de Direitos Humanos. 4.ed. São Paulo: Saraiva, 2015. 
REZEK, F. Prefácio. In: CALDEIRA BRANT, L. N. A autoridade da coisa julgada no Direito Interacional Público. Rio de Janeiro: Forense, 2002.

LUCK, A. S. O sistema internacional de direitos humanos. Disponível em: <http:// www.ambitouridico.com.br/site/index.php?n_link=revista_artigos=7067>. Acesso em: 10 maio. 2016.

SOARES, R. M. F. O princípio constitucional da dignidade da pessoa humana. São Paulo: Saraiva, 2010. 